\title{
Effect of breastfeeding on asthma, lung function and bronchial hyperreactivity in
} ISAAC Phase II

\author{
G. Nagel, G. Büchele, G. Weinmayr, B. Björkstén, Y-Z. Chen, H. Wang, W. Nystad, \\ Y. Saraclar, L. Bråbäck, J. Batlles-Garrido, G. Garcia-Hernandez, \\ S.K. Weiland $\uparrow$ and the ISAAC Phase II Study Group
}

ABSTRACT: The association between breastfeeding and wheezing, lung function and atopy was evaluated in the International Study of Asthma and Allergy in Childhood (ISAAC) Phase II.

Cross-sectional studies were performed in 27 centres in 20 countries. Information on disease and exposure factors was collected by parental questionnaires. Data from 54,000 randomly selected school children (aged 8-12 yrs, 31,759 with skin prick testing) and a stratified subsample $(n=4,888)$ were used for testing the correlation of breastfeeding with bronchial hyperreactivity and lung function. Random effect models for meta-analysis were applied to calculate combined odds ratios (ORs).

Any breastfeeding was associated with less wheeze both in affluent (adjusted OR (ORadj) 0.87, 95\% confidence interval $(\mathrm{Cl}) 0.78-0.97$ ) and nonaffluent countries (ORadj $0.80,95 \% \mathrm{Cl} 0.68-0.94$ ). Further analyses revealed that this was true only for nonatopic wheeze in nonaffluent countries (ORadj $0.69,95 \% \mathrm{Cl}$ 0.53-0.90). Breastfeeding was not associated with atopic wheeze and objective measures of allergy in both affluent and nonaffluent countries. In contrast, breastfeeding was associated with higher predicted forced expiratory volume in one second in affluent countries only (mean ratio $1.11,95 \% \mathrm{Cl} 1.02-1.20$ ).

Breastfeeding is associated with protection against nonatopic wheeze, which becomes particularly evident in nonaffluent countries. Overall, breastfeeding was not related to any measure of allergy. These findings may explain some of the controversy regarding breastfeeding, since the direction of the association with breastfeeding depends on the predominating wheeze phenotype (e.g. atopic, nonatopic).

KEYWORDS: Asthma, atopy, breastfeeding, bronchial hyperreactivity, children, International Study of Asthma and Allergy in Childhood

$\mathrm{H}$ uman milk contains numerous components that provide the infant with both passive protection against infections and components that enhance the maturation of the immune system [1]. Various possible biological mechanisms by which breast milk may influence atopic disease have been reported (e.g. via secretory immunoglobulin (Ig) A, antigens, cytokines, chemokines, polyunsaturated fatty acids (PUFA) and polyamines) [2]. In developing countries, breastfeeding reduces the incidence of infections, particularly gastrointestinal infections, while in affluent countries the effects are less apparent [3]. Despite numerous studies over the past 45 yrs addressing the possible protective effects of breastfeeding against the development of allergic disease this is still a controversial issue $[4,5]$. A study by VAN ODIJK et al. [6] reviewed the literature on breastfeeding and the risk of allergic disease from 1966 to 2001 and concluded that breastfeeding seems to be a protective factor for the development of atopic disease. The inverse association was stronger in children with atopic heredity. However, the authors excluded many of the reviewed papers due to noninformative findings and did not clearly differentiate between allergic and nonallergic origin of clinical symptoms. A meta-analysis by GDALEVICH et al. [7] included 12 studies that reported an overall protective effect of breastfeeding on asthma, especially in children with a hereditary risk for atopy.
AFFILIATIONS

For affiliations and a full list of the ISAAC Phase II Study group members, see Acknowledgments section.

CORRESPONDENCE

G. Nagel

Institute of Epidemiology

UIm University

Helmholtzstr 22

89081 UIm

Germany

Fax: 497315031069

E-mail: gabriele.nagel@uni-ulm.de

Received:

May 192008

Accepted after revision:

December 222008

\section{SUPPORT STATEMENT}

The coordination and central laboratory analyses of the European centres were funded by the Fifth

Framework Programme of the European Commission (QLK4-CT1999-01288; Brussels, Belgium). ALK (Hørsholm, Denmark) generously provided reagents for field work in several low income countries without charge.

STATEMENT OF INTEREST A statement of interest for this study can be found at www.erj.ersjournals.com/misc/ statements.dtl 
In a recent review, FRIEDMAN and ZEIGER [4] tried to identify reasons for heterogeneous results for the relationship between breastfeeding and the development of allergies and asthma. The results of previous studies were categorised according to neutral or allergy-inducing effects of breastfeeding [8-10] and a protective effect of breastfeeding [11-14]. Some of the inconsistency in the published literature may be caused by incomplete control for potential confounding differences in the investigated age group and outcome definition, such as the focus on atopic dermatitis [10, 14]. Most of the epidemiological studies included in the reviews were from affluent countries. However, the relationship of breastfeeding to wheezing may be different in less affluent populations with a higher burden of infectious disease and low prevalence of allergies.

The present authors' aim was to examine associations of breastfeeding practice with asthma among children aged 8$12 \mathrm{yrs}$ in a large international study using data from 20 countries. By applying highly standardised methodology and objective measurements the current authors wanted to minimise variability to differences in the way data were collected and also explored whether atopic status or sex modifies these associations.

\section{MATERIALS AND METHODS}

The rationale and methods of the International Study on Allergies and Asthma in Childhood (ISAAC) Phase II have already been described in detail elsewhere [15]. In brief, random samples of $\geqslant 10$ schools in a defined geographical area were chosen and children in classes where the majority of children were aged 9-11 yrs $(n \geqslant 1,000$ per centre) were invited to participate. Overall, $\sim 63,000$ schoolchildren $(76.4 \%$ of those eligible) took part. Parental questionnaires identical to those used in ISAAC Phase I [16] were used to collect data on allergies and asthma. For the present analyses, 54,943 children aged 8-12 yrs, from 27 centres in 20 countries were included, with a complete set of parental responses on breastfeeding.

\section{Exposure assessment}

Data on breastfeeding were collected retrospectively by parental questionnaire using the questions. "Was your child ever breastfed?" (yes/no) and "If yes, for how long?" ( $<6$ months $/ 6-12$ months $>1 \mathrm{yr}$ ), and the duration of breastfeeding was categorised as never breastfed, or breastfed for $<6$ months or $\geqslant 6$ months. Exclusiveness of breastfeeding was assessed by the question. "If yes, for how long was your child breastfed without adding other foods or juices?" ( $<2$ months / 2-4 months/5-6 months/>6 months). Time of exclusive breastfeeding was categorised as never breastfed, or breastfed for $<2$ months, $2-4$ months and $\geqslant 4$ months. The following potential confounders were considered: sex, age of the child (yrs), exposure to environmental tobacco smoke (ETS) at present ("Does anybody, at present, smoke inside your child's home?" (yes/no)), present bedroom sharing with other persons (yes/no) and maternal atopic disease ("has the child's mother ever had any of the following diseases: asthma, hay fever or eczema?"' (yes/no)).

The ISAAC Phase II protocol allowed objective measurements to be performed either in the full sample or in stratified subsamples of children [15]. Most centres invited all children for a skin prick test (SPT), while blood samples were collected mostly in subsamples of children stratified according to their wheezing status during the past year ( $\sim 100$ wheezers and 100 nonwheezers per centre). The stratified subsampling was applied by most centres for lung function measurements and bronchial hyperreactivity (BHR) testing. Approval of the local ethics committees was obtained by all centres [15].

As a difference was suspected in the strength of any association between breastfeeding and wheezing, asthma and allergy in affluent and nonaffluent countries, the study centres were classified into two broad categories on the basis of gross national income (GNI) per capita, converted into USA dollars, using the World Bank Atlas method [17]. All centres from countries which were classified by the World Bank as "high income countries" were combined in one group called affluent countries. The remaining centres were combined as nonaffluent countries (GNI <US\$9,200 per capita in 2001).

\section{Outcome}

The question "Has your child had wheezing or whistling in the chest in the past 12 months?" was used as the indicator for childhood asthma. In addition, the lifetime prevalence of asthma was investigated using the question "Has your child ever had asthma?" SPTs were performed on 31,759 children using six common aeroallergens: Dermatophagoides pteronyssinus, Dermatophagoides farinae, cat hair, Alternaria tenuis and mixed tree and grass pollen (ALK-Albelló, Hørsholm, Denmark). In addition, data on locally relevant allergens tested in 15 centres were included. For this analysis at least one positive reaction (wheal size $\geqslant 3 \mathrm{~mm}$ after subtraction of the negative control) was defined as a positive SPT. Atopic wheeze was defined as wheeze during the past year and a positive SPT [18].

Spirometry was performed according to the American Thoracic Society criteria [19]. At least two spirograms were recorded, and the higher of two reproducible measurements (with $<5 \%$ variation) of forced expiratory volume in one second (FEV1) was recorded as baseline value. Values of FEV1 $\%$ predicted were used as a descriptor of lung function and were calculated based on age, weight (except Albania and the UK) and height stratified for sex and centre by linear regression models. High FEV1 \% pred indicates good lung function.

As described elsewhere in detail [15] BHR was assessed using a DeVilbiss nebuliser (Sunrise Medical, Malsch, Germany) by further measurements of FEV1 after inhalation of nebulised hyperosmolar saline (4.5\%) for increasing time periods $(0.5,1,2$, 4 and $8 \mathrm{~min}$ ) [20]. FEV1 was measured $1 \mathrm{~min}$ after the end of each inhalation period and the next challenge was performed after $3 \mathrm{~min}$ wash-out time. If FEV1 fell $10-15 \%$ below the baseline value, the previous exposure time was repeated. If after two repetitions the fall of FEV1 was still between $10 \%$ and $15 \%$, the exposure time was also doubled. Bronchial challenge was stopped if either the FEV1 had fallen by $\geqslant 15 \%$ or the total inhalation period of $15.5 \mathrm{~min}$ had been reached. In children with a baseline FEV1 of $<75 \%$ pred, no bronchial challenge was performed and an inhaled bronchodilator was administered.

\section{Statistical analysis}

For stratified subsamples, weighted prevalences and risk estimates were calculated [21]. Random effect models for 
meta-analysis were applied to calculate crude and adjusted odds ratios (ORs) or mean ratios (MRs) for FEV1\% pred with $95 \%$ confidence intervals (CI) combined for affluent and nonaffluent countries [22]. The following potential confounders were considered: sex and age of the child, in order to control for age or sex differences; exposure to ETS at present, to control for respiratory symptoms due to tobacco smoke; present bedroom sharing with other persons, used to control for family size and living conditions; and maternal atopic disease, to control for an increased risk of atopy and potential lifestyle modifications. Heterogeneity between centres was estimated from random effect meta-analysis was tested with the Wald statistics ( $p$-value). In case of heterogeneity, fixed random effect models were calculated and a statistical test on differences of the study means based on the Chi-squared distribution was performed (Pfixed). Interaction was investigated by including a product term in the logistic regression equation.

Depending on the prevalence and completeness of the variables, the number of subjects and sometimes the number of centres/countries in the models differed if some subjects/ centres did not contribute any information and, therefore, had to be excluded.

All calculations were performed and stratified by each centre and the combined estimates for affluent and nonaffluent countries are shown. Further stratification by maternal atopic disease, sex and atopic and nonatopic wheeze was performed.

\section{RESULTS}

Table 1 shows the basic characteristics of the study populations. The prevalence of any breastfeeding ranged between $26.4 \%$ in Hong Kong (China) to $100 \%$ in Pichincha (Ecuador). The proportion of children reporting wheeze during the past year ranged from $0.8 \%$ in Pichincha (Ecuador) to $25.6 \%$ in Uruguaiana (Brazil). The lifetime prevalence of asthma ranged between $2.7 \%$ in Tirana (Albania) to $35.6 \%$ in Hawkes Bay (New Zealand). Among breastfed children, mothers with atopic disease and bedroom sharing were more prevalent than among nonbreastfed children.

Table 2 shows the crude and adjusted associations between breastfeeding and wheeze during the past year. In the multivariate models, breastfeeding was inversely associated with wheeze during the past year, both in affluent countries (adjusted OR (ORadj) 0.87, 95\% CI 0.78-0.97; $\mathrm{p}=0.50$ ) and in nonaffluent countries (ORadj 0.80, 95\% CI 0.68-0.94; $\mathrm{p}=0.50$ ). Although going in the expected direction, no significant effect was found for the duration of breastfeeding in affluent countries, whereas in nonaffluent countries breastfeeding for $\geqslant 6$ months was associated with less wheeze (ORadj 0.74, 95\% CI $0.62-0.88 ; p=0.25)$. In affluent countries, the duration of exclusive breastfeeding tended to be inversely associated with wheeze, but reached statistical significance only for the category 2-4 months. However, in nonaffluent countries exclusive breastfeeding for $\geqslant 2$ months (ORadj 0.77, 95\% CI 0.63-0.94; $\mathrm{p}=0.17$ ) and $>4$ months (ORadj $0.74,95 \%$ CI $0.61-0.90 ; \mathrm{p}=0.47$ ) was inversely associated with wheeze. In addition, any breastfeeding was related to a reduced lifetime prevalence of asthma in affluent countries (ORadj 0.87, 95\% CI 0.78-0.97) and a similar trend was noted in nonaffluent countries (ORadj 0.89, 95\% CI 0.71-1.11; table 3).

Breastfeeding showed no significant relationship with atopic wheeze for either affluent (ORadj 0.85, 95\% CI 0.67-1.08; $\mathrm{p}=0.13$ ) or nonaffluent countries (ORadj $0.86,95 \%$ CI 0.55-1.35; $\mathrm{p}=0.27$; table 4 ). For nonatopic wheeze, the inverse association with breastfeeding was stronger in nonaffluent countries (ORadj 0.69, 95\% CI 0.53-0.90; Pfixed 0.98) than affluent countries (ORadj 0.87, 95\% CI 0.72-1.06; p=0.48). Moreover, no associations were found between breastfeeding practice and positive SPT or elevated specific IgE levels, either in affluent or nonaffluent countries (see online supplementary material).

The associations between any breastfeeding and wheeze were not affected by maternal atopy in affluent (ORadj 0.93, 95\% CI $0.79-1.10, \mathrm{p}=0.50$ and ORadj $0.82,95 \%$ CI $0.71-0.95, \mathrm{p}=0.50$, respectively), or in nonaffluent countries (ORadj 0.78, 95\% CI $0.48-1.27, \mathrm{p}=0.23$ and ORadj $0.80,95 \%$ CI $0.66-0.96, \mathrm{p}=0.50$, respectively). In affluent countries, the inverse association between breastfeeding and wheeze was more pronounced for females (ORadj 0.78, 95\% CI 0.64-0.95; Pfixed 0.69) than for males (ORadj 0.95, 95\% CI 0.83-1.10; Pfixed 0.91), while the opposite was true in nonaffluent countries (ORadj 0.73, 95\% CI $0.56-0.95, p=0.33$ in males versus ORadj $0.82,95 \%$ CI $0.64-1.05$, $\mathrm{p}=0.49$ in females). When all countries were combined, there was no significant effect modification by $\operatorname{sex}(\mathrm{p}=0.455)$.

Breastfeeding tended to be inversely related to BHR in affluent and nonaffluent countries, but none of the associations were statistically significant (ORadj 0.92, 95\% CI 0.75-1.12; $\mathrm{p}=0.50$ and ORadj 0.66, 95\% CI 0.37-1.20, p=0.50, respectively; fig. 1a). However, breastfed children tended to have better lung function as determined by FEV1\% in affluent countries (MR 1.11, 95\% CI 1.02-1.20; $\mathrm{p}=0.42$ ), but not in nonaffluent countries (MR $0.89,95 \%$ CI $0.68-1.17$; $p=0.30$; fig. $1 b$ ). This interaction with affluence was not significant $(\mathrm{p}=0.564)$.

\section{DISCUSSION}

In line with some of the previous literature [6, 7, 11-14, 23], but in contrast to some other reports $[9,10,24]$, the present authors observed an inverse association between breastfeeding and wheezing. This was particularly true in nonaffluent countries. Breastfeeding for $\geqslant 6$ months, and $>2$ months of exclusive breastfeeding, were associated with less wheeze in nonaffluent countries, while there was no consistent evidence that the duration of breastfeeding was associated with asthma in affluent countries. Furthermore, the protective effect of breastfeeding against childhood wheezing was limited to nonatopic wheeze, while IgE-associated wheeze and atopic sensitisation were not affected. The current findings could explain at least some of the current controversy regarding the relationship between breastfeeding and wheezing later in childhood. While overall there was a protective effect of breastfeeding against wheeze, in reality it was evident only for nonatopic wheeze in nonaffluent countries. In affluent countries, where wheezing is more commonly associated with allergy, breastfeeding showed no relationship with wheeze, despite the large sample size. Depending on the predominant wheeze phenotype in populations, an association between breastfeeding and wheeze may appear. 


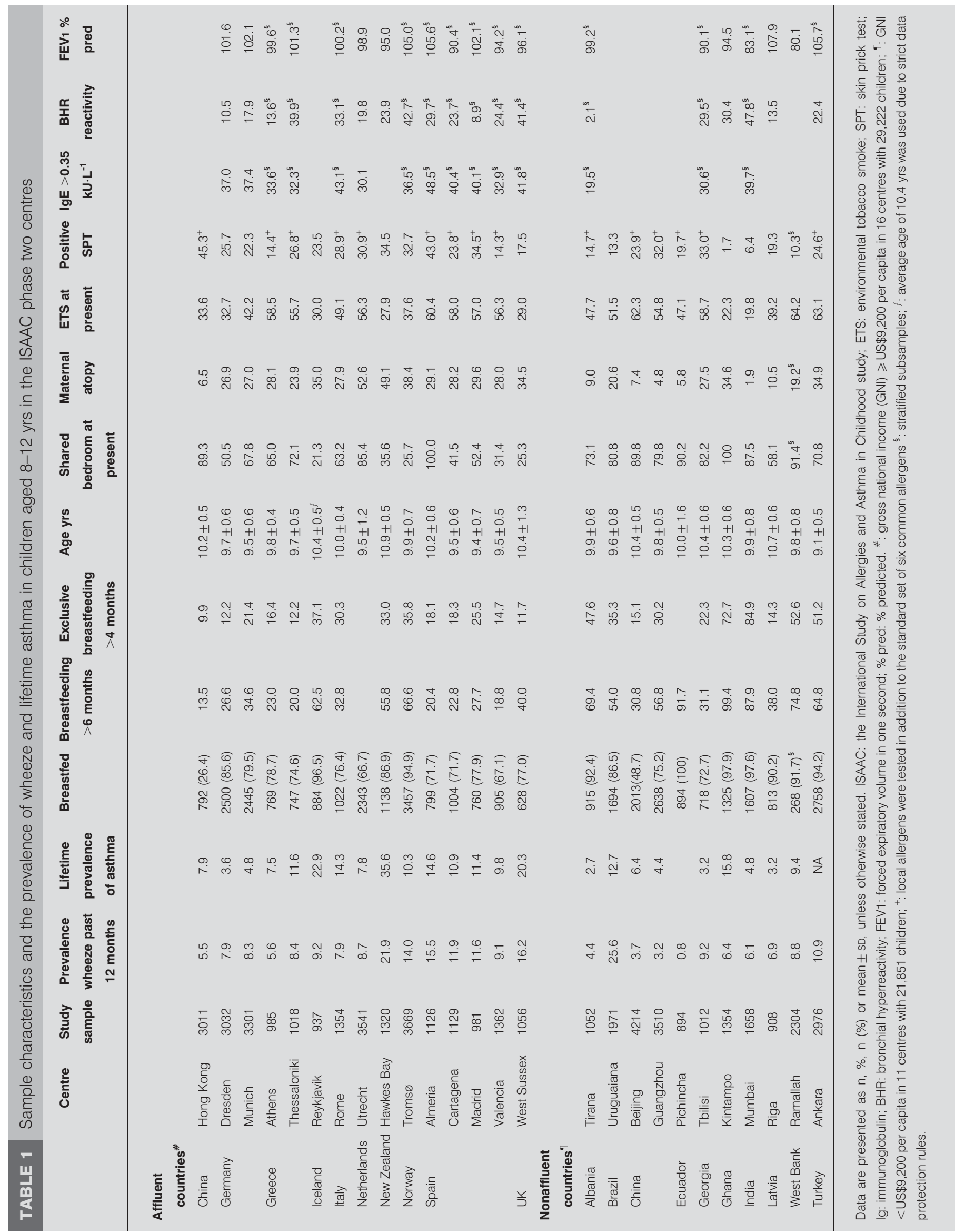


TABLE 2 Association between breastfeeding practice and wheeze in the previous year by affluence ${ }^{\#}$

\begin{tabular}{|c|c|c|c|c|c|c|c|c|}
\hline & \multicolumn{4}{|c|}{ Affluent countries } & \multicolumn{4}{|c|}{ Nonaffluent countries ${ }^{+}$} \\
\hline & \multicolumn{2}{|c|}{ Crude } & \multicolumn{2}{|c|}{ Adjusted $^{\S}$} & \multicolumn{2}{|c|}{ Crude } & \multicolumn{2}{|c|}{ Adjusted $^{\S}$} \\
\hline \multicolumn{9}{|l|}{ Breastfeeding ${ }^{f}$} \\
\hline \multicolumn{9}{|c|}{ Duration of breastfeeding ${ }^{\# \#}$} \\
\hline Not breastfed & 1 & Reference & 1 & Reference & 1 & Reference & 1 & Reference \\
\hline$<6$ months & 0.91 & $0.8-1.03$ & 0.88 & $0.78-1.00$ & 0.94 & $0.76-1.16$ & 0.95 & $0.73-1.23$ \\
\hline$\geqslant 6$ months & 0.89 & $0.77-1.04$ & 0.88 & $0.76-1.03$ & 0.75 & $0.63-0.89$ & 0.74 & $0.62-0.88$ \\
\hline$\geqslant 4$ months & 0.93 & $0.80-1.08$ & 0.92 & $0.78-1.10$ & 0.74 & $0.61-0.89$ & 0.74 & $0.61-0.90$ \\
\hline
\end{tabular}

TABLE 3 Associations between breastfeeding practice and lifetime prevalence of asthma ${ }^{\#}$ by affluence

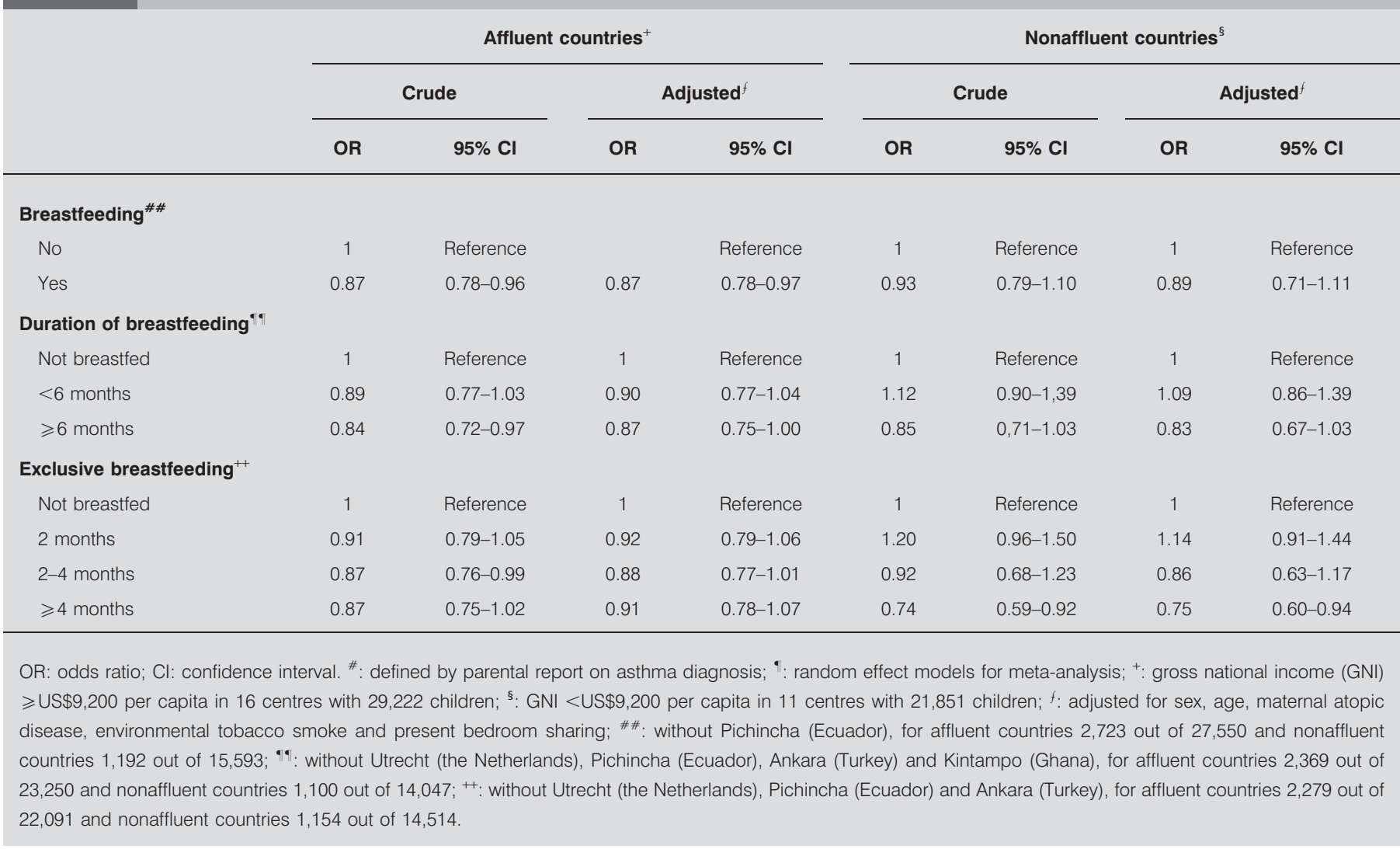


TABLE 4 Association of breastfeeding practice with atopic and nonatopic wheeze ${ }^{\#}$ during the previous year by affluence

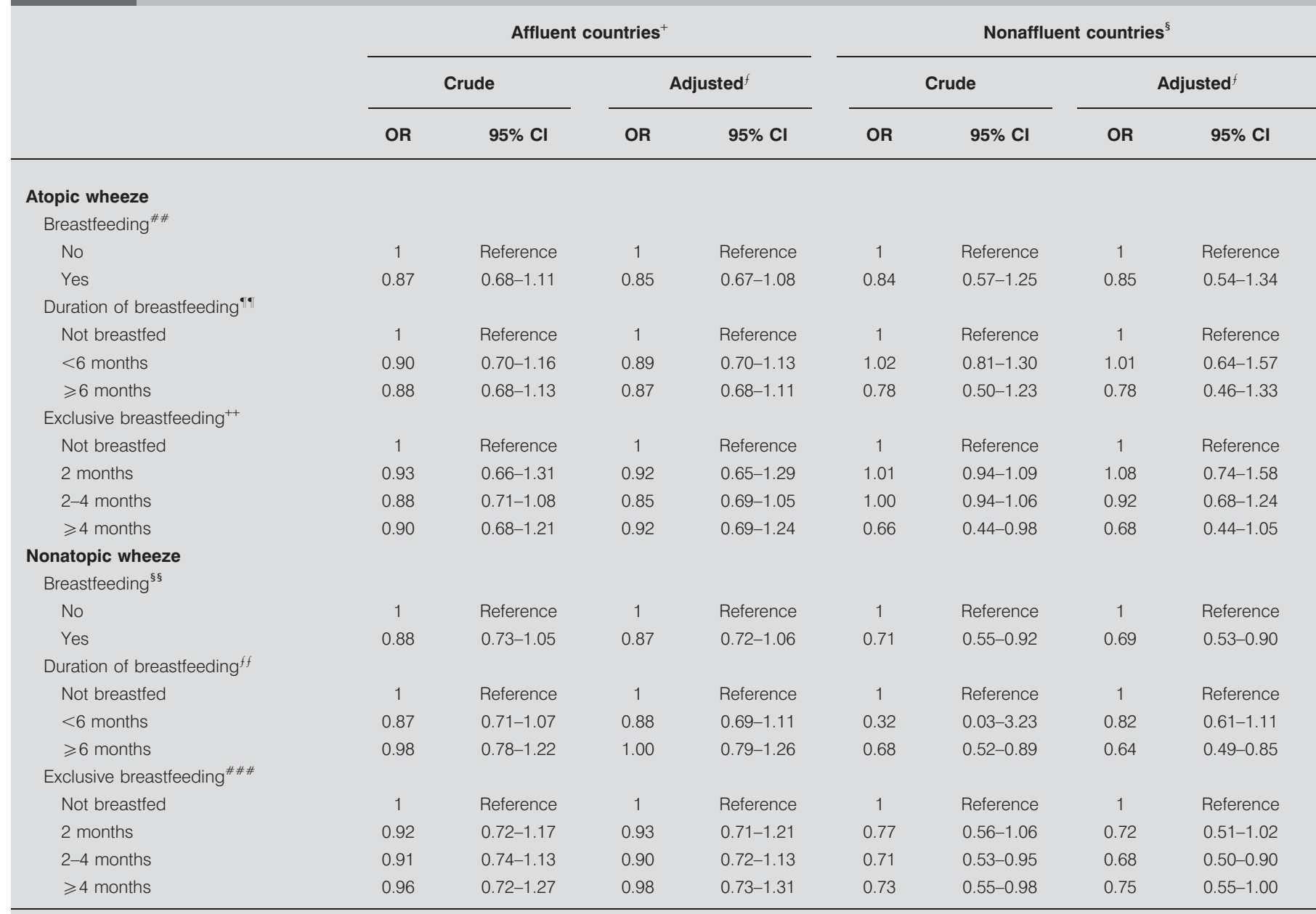

OR: odds ratio; Cl: confidence interval. \#: defined as wheeze with (atopic) and without (nonatopic) skin prick test positivity; ": random effect models for meta-analysis; + : gross national income (GNI) $\geqslant U S \$ 9,200$ per capita in 16 centres with 29,222 children; ${ }^{\text {s: }}$ GNI <US $\$ 9,200$ per capita in 11 centres with 21,851 children; ; : adjusted for

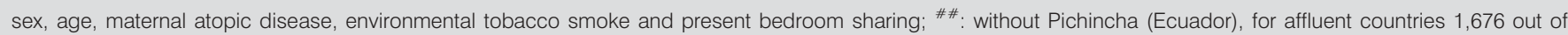
15,610 and nonaffluent countries 907 out of 8,503; " $\%$ : without Utrecht (the Netherlands), Pichincha (Ecuador), Kintampo (Ghana) and Ramallah (West Bank), for affluent countries 1,514 out of 13,646 and nonaffluent countries 805 out of 6,$882 ;{ }^{++}$: without Utrecht (The Netherlands) and Pichincha (Ecuador), for affluent countries 1,532 out of 13,894 and nonaffluent countries 906 out of 7,952; ${ }^{\S \S}$ : without Reykjavik (Iceland) and Pichincha (Ecuador), for affluent countries 1,676 out of 15,610 and for nonaffluent countries 1,004 out of 9,741; ff: for affluent countries 1,606 out of 14,580 and nonaffluent countries 1,027 out of 10,723; \#\#\#: without Reykjavik (Iceland), Utrecht (the Netherlands), Pichincha (Ecuador) and Kintampo (Ghana), for affluent countries 1,429 out of 12,776 and nonaffluent countries 818 out of 7,173.

Other authors found breastfeeding for $\geqslant 4$ months to be associated with less wheeze, compared with children who were never breastfed [12, 25]. Results from a recent randomised intervention study on prolonged and exclusive breastfeeding revealed no protective effect on symptoms of allergies, asthma and SPT positivity among 6.5-yr-old children in Belarus [5]. The present results indicate no major reduction in the prevalence of prolonged breastfeeding or exclusive breastfeeding for $>4$ months in affluent countries in contrast to nonaffluent countries where the prevalence of wheeze was lower. There is evidence for age-dependent prevalence and phenotype patterns in children [26]. Different prevalences of the wheeze phenotypes nonatopic and atopic (IgE-associated) wheeze may explain the differential associations by affluence status. The present authors found favourable FEV1 \% values among breastfed children in affluent countries. Again, differences in the prevalence of nonatopic and atopic (IgEassociated) wheeze may explain the differential associations by affluence status.

The reviews by VAN ODIJK et al. [6] and GDALEVICH et al. [7] reported an overall protective effect of breastfeeding on asthma prevalence, especially in children with a family history of atopy. The current study, comprising 54,000 children in 20 countries, could not confirm this, as a slightly stronger inverse association with breastfeeding in children without maternal atopy in affluent but not in nonaffluent countries was observed.

There is more or less a consensus that breastfeeding offers protection against infections and thus also against wheezing in infancy $[1,2]$. Prospective studies have revealed that recurrent respiratory infections in infancy may indicate a predisposition 

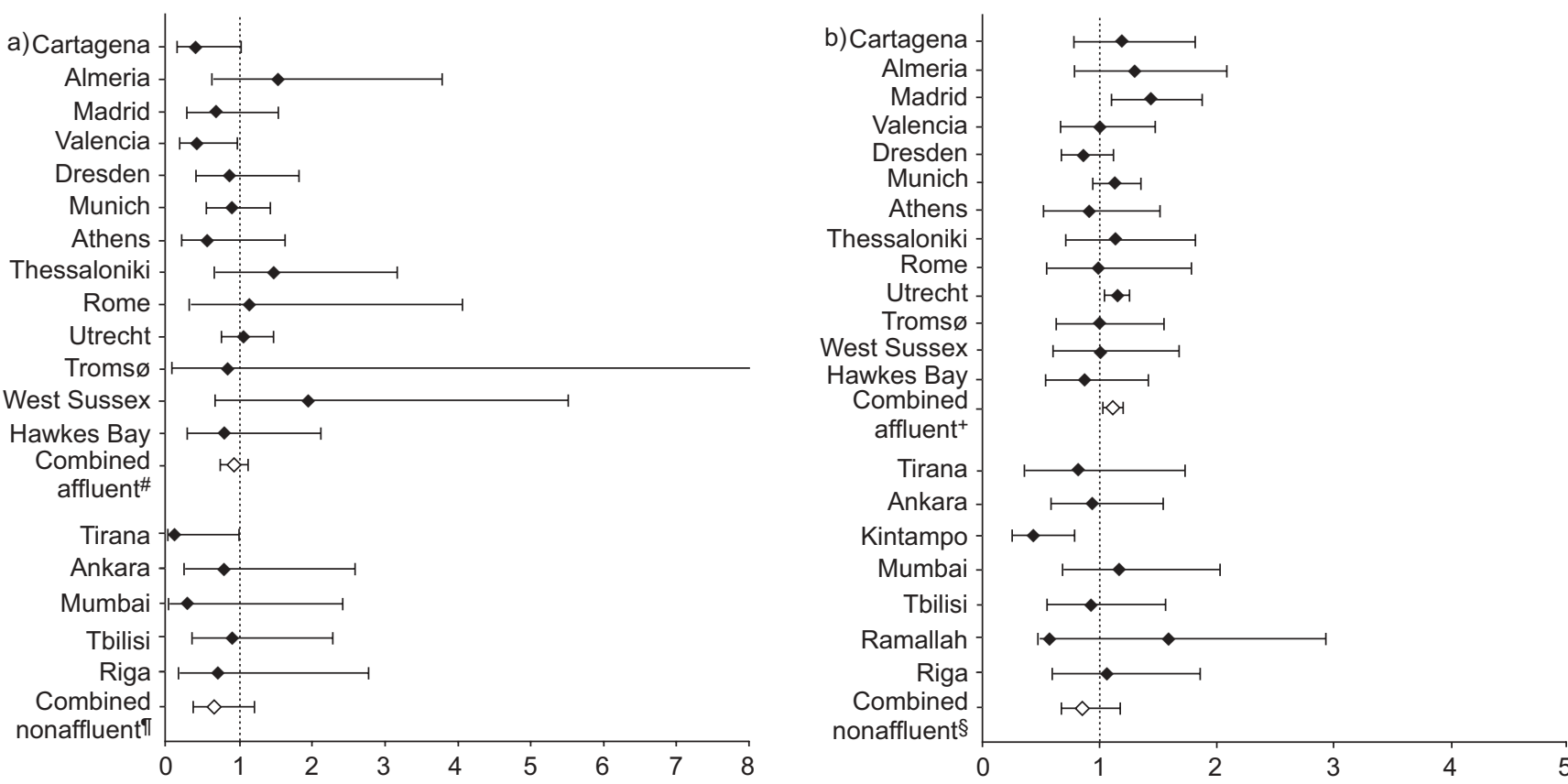

FIGURE 1. Meta-analysis random effect models for associations between a) breastfeeding and bronchial hyperreactivity (odds ratio (OR) and $95 \%$ confidence interval $(\mathrm{Cl})$ ) and b) breastfeeding and predicted forced expiratory volume in one second (means ratio (MR) and 95\% $\mathrm{Cl}$ ), adjusted for sex, age, maternal atopic disease, environmental tobacco smoke and present bedroom sharing. *: gross national income (GNI) $\geqslant U S \$ 9,200$ per capita in 13 centres with 4,028 children; ": GNI <US\$9,200 per capita in five centres with 860 children; $^{+}$: GNI $\geqslant U S \$ 9,200$ per capita in 13 centres with 6,348 children; ${ }^{\S}$ : GNI $<U S \$ 9,200$ per capita in seven centres with 1,376 children

$\diamond$ : OR or MR for each country; $\diamond$ : total OR or MR for affluent and nonaffluent countries; — : confidence intervals.

for wheezing and BHR [27, 28]. WRIGHT et al. [24] found that breastfeeding has a protective effect early in life, whereas it may be associated with an increased risk of asthma in adolescents, especially in atopic children of asthmatic mothers. Results of a cohort study from Australia suggest that the association between breastfeeding and asthma may depend on the age of manifestation, conferring protection up to the age of 7 yrs, but associated with an increased risk for asthma after this age [29]. As asthma is usually not associated with allergy during the first years of life, in contrast to the situation in older children, these findings would support the current observations that breastfeeding was associated with less wheezing but not less sensitisation and particularly so in nonaffluent countries.

Human milk contains various bioactive and immunomodulatory constituents, such as antibodies, oligosaccharides, cells and cytokines $[3,30]$. The composition of breast milk differs between allergic and nonallergic mothers and it has been suggested that this could explain some of the controversy regarding the possible allergy-preventive effects of breastfeeding [30]. In support of this, a Swedish study has shown that the composition of PUFA in breast milk not only differed between allergic and nonallergic mothers but also affected the development of allergic disease, at least up to the age of 2 yrs [31]. Such differences could also explain the observations by WRIGHT et al. [24] that children who were breastfed by allergic compared with nonallergic mothers had a higher incidence of allergies.

Breastfeeding may influence the immunological and respiratory function during early childhood [2]. A long-term immunological effect of breastfeeding is also supported by the observations that the thymus size was larger in breastfed than in nonbreastfed infants [32]. The effect of breastfeeding may depend on the age of asthma onset, with a stronger protective effect for early asthma onset $[12,29]$. In the present study, breastfeeding had favourable effects on wheeze during the previous year and particularly on nonatopic wheeze in nonaffluent countries, suggesting an infection-linked immune modulation. It is also possible that the composition of breast milk was affected by socioeconomic factors, maternal diet, pollutants, and the nature of microbiological exposure $[3,31]$.

After stratification by sex the protective effect of breastfeeding remained stronger in females than in males in affluent countries, whereas the opposite was found in nonaffluent countries. This observation is in agreement with another report concerning neonatal respiratory infections [33]. Other environmental factors, such as diet, infections or hormones, may further contribute to sex-specific patterns of associations between breastfeeding, asthma and allergies [34]. However, in the current study, breastfeeding was unrelated to either of the primary risks / cofactors of asthma (atopy and BHR), which supports the lack of relationship with atopic wheeze. In affluent societies, the protective effect of breastfeeding against nonatopic wheeze, which is probably mainly due to infections, is marginal, while it is a major factor in developing countries. This observation is corroborated by the findings that substantially higher fractions of current wheeze are attributable to SPT reactivity in affluent compared with nonaffluent countries [18]. In addition, lower prevalence rates of SPT reactivity were found in less affluent countries [18]. 
Some limitations have to be kept in mind. Since a crosssectional study was performed and the data on breastfeeding history were collected retrospectively, recall biases are likely, which may have affected more the duration and exclusiveness of breastfeeding than breastfeeding per se. In addition, no detailed information on early infections was available. Parental socioeconomic conditions varied within the centres and may have confounded observations. However, the calculation of models adjusting for years of maternal or paternal education as an indicator for socioeconomic position for the centres with available information did not substantially affect the associations. Multiple comparisons were performed, which need to be considered for the interpretation of the results. The application of well established and standardised questionnaires and methodology in the centres would support the consistency of the findings across centres in affluent and nonaffluent countries. In addition, objective markers of allergy sensitisation and lung function were applied. The current study added results from nonaffluent countries.

The present results provide evidence that breastfeeding is protective against nonallergic wheeze among children aged 8-12 yrs in nonaffluent societies. However, there was no protective relationship of breastfeeding with measures of allergy. These findings may explain some of the controversy regarding the long-term effects of breastfeeding on respiratory symptoms, as atopic (immunoglobulin E-associated) and nonatopic wheeze were clearly not separated in most previous studies. Depending on which type of wheeze phenotype predominates (e.g. atopic or nonatopic) at a particular age, breastfeeding may exert a protective or marginal effect on wheeze. Further research needs to consider differential pathways according to atopic and nonatopic wheeze phenotype.

\section{ACKNOWLEDGEMENTS}

The affiliations of the present authors are as follows. G. Nagel, G. Büchele, G. Weinmayr and S.K. Weiland: Institute of Epidemiology, Ulm University, Ulm, Germany. B. Björkstén: Institute of Environmental Medicine, Karolinska Institutet Stockholm, Stockholm, Sweden. Y-Z. Chen: Capital Institute of Paediatrics, Beijing, People's Republic of China. H. Wang: Guangzhou Institute of Respiratory Diseases, The First Affiliated Hospital of Guangzhou Medical College, Guangzhou, People's Republic of China, and Firestone Institute for Respiratory Health, St Joseph's Healthcare, and Dept of Medicine, McMaster University, Hamilton, ON, Canada. W. Nystad: Norwegian Institute of Public Health, Division of Epidemiology, Tromsø, Norway. Y. Saraclar: Dept of Paediatric Allergy and Asthma, Hacettepe University, Ankara, Turkey. L. Bråbäck: Dept of Public Health and Research, Sundsvall Hospital, Sundsvall, Sweden. J. Batles-Garrido: Paediatric Dept, Torrecárdenas Hospital, Almeria, Spain. G. Garcia-Hernandez: Paediatric Allergy and Pulmonology Unit, Doce de Octubre University Children's Hospital, Madrid, Spain.

The ISAAC II Steering Group consists of the following. B. Björkstén (Stockholm, Sweden), B. Brunekreef (Utrecht, the Netherlands), W. Cookson (Oxford, UK), D. Strachan (London, UK), E. von Mutius (Munich, Germany), and S.K. Weiland $\dagger$ (ISAAC II Coordinator; Ulm, Germany).
The present authors wish to thank all children, parents, teachers, field workers and laboratory workers for their enormous contributions to this collaborative study and A. Kleiner (Ulm, Germany) for her excellent technical assistance.

S.K. Weiland, head of the Institute of Epidemiology, Ulm University (Ulm, Germany), died suddenly and unexpectedly on March 19, 2007. The present authors will always remember him as a generous and supportive mentor and as a great scientist with a genuine enthusiasm for international collaboration.

The ISAAC II Coordinating and Data Centre consists of the following. G Büchele, A. Kleiner, G. Nagel, P. Rzehak, G. Weinmayr and S.K. Weiland $\dagger$ (Director; all Institute of Epidemiology, Ulm University, Germany).

The following are Principal Investigators and members of the Scientific Team. A. Priftanji, A. Shkurti, J. Simenati, E. Grabocka, K. Shyti, S. Agolli and A. Gurakuqi (Tirana, Albania); R.T. Stein, M. Urrutia de Pereira, M.H. Jones and P.M. Pitrez (Uruguaiana, Brazil); P.J. Cooper and M. Chico (Pichincha province, Ecuador); Y.Z. Chen (Bejing), N.S. Zhong (Guangzhou) and C. Lei (National Coordinator; Hong Kong, all China); G. Wong, M-A. Riikjärv and T. Annus (Tallinn, Estonia); I. Annesi-Maesano (Créteil, France); M. Gotua, M. Rukhadze, T. Abramidze, I. Kvachadze, L. Karsanidze, M. Kiladze and N. Dolidze (Tblisi, Georgia); W. Leupold, U. Keil, E von Mutius and S.K. Weiland $\dagger$ (Dresden, Germany); E. von Mutius, U. Keil and S.K. Weiland $\dagger$ (Munich, Germany); P. Arthur $\dagger$ and E. Addo-Yobo (Kintampo, Ghana); C. Gratziou (National Coordinator), C. Priftis, A. Papadopoulou and C. Katsardis (Athens, Greece); J. Tsanakas, E. Hatziagorou, F. Kirvassilis (Thessaloniki, Greece); M. Clausen (Reykjavik, Iceland); J.R. Shah, R.S. Mathur, R.P. Khubchandani and S. Mantri (Mumbai, India); F. Forastiere, R. Di Domenicantonio, M. De Sario, S. Sammarro, R. Pistelli, M.G. Serra, G. Corbo and C.A. Perucci (Rome, Italy); V. Svabe, D. Sebre, G. Casno, I. Novikova and L. Bagrade (Riga, Latvia); B. Brunekreef, D. Schram, G. Doekes, P.H.N. Jansen-van Vliet, N.A.H. Janssen, F.J.H. Aarts and G. de Meer (Utrecht, the Netherlands); J. Crane, K. Wickens and D. Barry (Hawkes Bay, New Zealand); W. Nystad, R. Bolle and E. Lund (Tromsø, Norway); N. El-Sharif, B. Nemery, F. Barghuthy, S. Abu Huij and M. Qlebo (Ramallah, West Bank); J. Batlles Garrido, T. Rubi Ruiz, A. Bonillo Perales, Y. Gonzalez Jiménez, J. Aguirre Rodriguez, J. Momblan de Cabo, A. Losilla Maldonado and M. Daza Torres (Almeria, Spain); L. GarciaMarcos (National Coordinator), A. Martinez Torres, J.J. Guillén Pérez, A. Piñana López and S. Castejon Robles (Cartagena, Spain); G. Garcia Hernandez, A. Martinez Gimeno, A.L. Moro Rodríguez, C. Luna Paredes and I. Gonzalez Gil (Madrid, Spain); M.M. Morales Suarez-Varela, A. Llopis González, A. Escribano Montaner and M. Tallon Guerola (Valencia, Spain); L. Bråbäck (National Coordinator), M. Kjellman, L. Nilsson and X-M. Mai (Linköping, Sweden); L. Bråbäck and A. Sandin (Östersund, Sweden); Y. Saraçlar, S. Kuyucu, A. Tuncer, C. Saçkesen, V. Sumbuloğlu, P. Geyik and C. Kocabaş (Ankara, Turkey); D. Strachan and B. Kaur (West Sussex, UK).

The ISAAC Steering Committee includes the following. N. AitKhaled (Paris, France); H.R. Anderson and D.P. Strachan 
(London, UK); W. Cookson (Oxford, UK); H. Williams (Nottingham, UK); I. Asher, P. Ellwood, E. Mitchell and A. Stewart (Auckland, New Zealand); J. Crane, R. Beasley and N. Pearce (Wellington, New Zealand); B. Björkstén (Stockholm, Sweden); B. Brunekreef (Utrecht, the Netherlands); S. Foliaki (Nuku'alofa, Kingdom of Tonga); L. García-Marcos (Murcia, Spain); U. Keil and E. von Mutius (Munich, Germany); S.K. Weiland $\dagger$ (Ulm, Germany); C. Lai and G. Wong (Hong Kong, China); J. Mallol (Santiago, Chile); S. Montefort (Naxxar, Malta); J. Odhiambo (Nairobi, Kenya); C. Robertson (Parkville, Australia).

The agencies funding the field work are listed elsewhere [15].

\section{REFERENCES}

1 Howie PW, Forsyth JS, Ogston SA, Clark A, Florey CD. Protective effect of breast feeding against infection. BMJ 1990; 300: 11-16.

2 Wills-Karp M, Brandt D, Morrow AL. Understanding the origin of asthma and its relationship to breastfeeding. Adv Exp Med Biol 2004; 554: 171-191.

3 Labbok MH, Clark D, Goldman AS. Breastfeeding: maintaining an irreplaceable immunological resource. Nat Rev Immunol 2004; 4: 565-572.

4 Friedman NJ, Zeiger RS. The role of breast-feeding in the development of allergies and asthma. J Allergy Clin Immunol 2005; 115: 1238-1248.

5 Kramer MS, Matush L, Vanilovich I, et al. Effect of prolonged and exclusive breast feeding on risk of allergy and asthma: cluster randomised trial. BMJ 2007; 335: 815.

6 van Odijk J, Kull I, Borres MP, et al. Breastfeeding and allergic disease: a multidisciplinary review of the literature (1966-2001) on the mode of early feeding in infancy and its impact on later atopic manifestations. Allergy 2003; 58: 833-843.

7 Gdalevich M, Mimouni D, David M, Mimouni M. Breastfeeding and the onset of atopic dermatitis in childhood: a systematic review and meta-analysis of prospective studies. J Am Acad Dermatol 2001; 45: 520-527.

8 Rusconi F, Galassi C, Corbo GM, et al. Risk factors for early, persistent, and late-onset wheezing in young children. SIDRIA Collaborative Group. Am J Respir Crit Care Med 1999; 160: 1617-1622.

9 Sears MR, Greene JM, Willan AR, et al. Long-term relation between breastfeeding and development of atopy and asthma in children and young adults: a longitudinal study. Lancet 2002; 360: 901-907.

10 Bergmann RL, Diepgen TL, Kuss O, et al. Breastfeeding duration is a risk factor for atopic eczema. Clin Exp Allergy 2002; 32: 205-209.

11 Kramer MS, Chalmers B, Hodnett ED, et al. Promotion of Breastfeeding Intervention Trial (PROBIT): a randomized trial in the Republic of Belarus. JAMA 2001; 285: 413-420.

12 Kull I, Almqvist C, Lilja G, Pershagen G, Wickman M. Breast-feeding reduces the risk of asthma during the first 4 years of life. J Allergy Clin Immunol 2004; 114: 755-760.

13 Oddy WH, Peat JK, de Klerk NH. Maternal asthma, infant feeding, and the risk of asthma in childhood. J Allergy Clin Immunol 2002; 110: 65-67.
14 Laubereau B, Brockow I, Zirngibl A, et al. Effect of breastfeeding on the development of atopic dermatitis during the first 3 years of life - results from the GINI-birth cohort study. J Pediatr 2004; 144: 602-607.

15 Weiland SK, Bjorksten B, Brunekreef B, Cookson WO, von Mutius E, Strachan DP. Phase II of the International Study of Asthma and Allergies in Childhood (ISAAC II): rationale and methods. Eur Respir J 2004; 24: 406-412.

16 Asher MI, Keil U, Anderson HR, et al. International Study of Asthma and Allergies in Childhood (ISAAC): rationale and methods. Eur Respir J 1995; 8: 483-491.

17 The World Bank Group. World Bank Atlas Method. http://web.worldbank.org/WBSTTE/EXTERNAL/ DATASTATISTICS/0,,contentMDK:20452009 isCURL:Y menuPK:64133156 pagePK:64133150 piPK:64133175 theSitePK:239419,00.html Date last accessed: March 17, 2009.

18 Weinmayr G, Weiland SK, Bjorksten B, et al. Atopic sensitization and the international variation of asthma symptom prevalence in children. Am J Respir Crit Care Med 2007; 176: 565-574.

19 Miller MR, Hankinson J, Brusasco V, et al. Standardisation of spirometry. Eur Respir J 2005; 26: 319-338.

20 Riedler J, Reade T, Dalton M, Holst D, Robertson C. Hypertonic saline challenge in an epidemiologic survey of asthma in children. Am J Respir Crit Care Med 1994; 150: 1632-1639.

21 Richardson DB, Rzehak P, Klenk J, Weiland SK. Analyses of case-control data for additional outcomes. Epidemiology 2007; 18: 441-445.

22 Normand SL. Meta-analysis: formulating, evaluating, combining, and reporting. Stat Med 1999; 18: 321-359.

23 Kull I, Wickman M, Lilja G, Nordvall SL, Pershagen G. Breast feeding and allergic diseases in infants - a prospective birth cohort study. Arch Dis Child 2002; 87: 478-481.

24 Wright AL, Holberg CJ, Taussig LM, Martinez FD. Factors influencing the relation of infant feeding to asthma and recurrent wheeze in childhood. Thorax 2001; 56: 192-197.

25 Oddy WH, Holt PG, Sly PD, et al. Association between breast feeding and asthma in 6 year old children: findings of a prospective birth cohort study. BMJ 1999; 319: 815-819.

26 Frank PI, Morris JA, Hazell ML, Linehan MF, Frank TL. Long term prognosis in preschool children with wheeze: longitudinal postal questionnaire study 1993-2004. BMJ 2008; 336: 1423-1426.

27 Oddy WH, de Klerk NH, Sly PD, Holt PG. The effects of respiratory infections, atopy, and breastfeeding on childhood asthma. Eur Respir J 2002; 19: 899-905.

28 Stein RT, Sherrill D, Morgan WJ, et al. Respiratory syncytial virus in early life and risk of wheeze and allergy by age 13 years. Lancet 1999; 354: 541-545.

29 Matheson MC, Erbas B, Balasuriya A, et al. Breastfeeding and atopic disease: A cohort study from childhood to middle age. J Allergy Clin Immunol 2007; 120: 1051-1057.

30 Bottcher MF, Jenmalm MC, Garofalo RP, Bjorksten B. Cytokines in breast milk from allergic and nonallergic mothers. Pediatr Res 2000; 47: 157-162. 
31 Duchen K, Bjorksten B. Polyunsaturated n-3 fatty acids and the development of atopic disease. Lipids 2001; 36: 1033-1042.

32 Jeppesen DL, Hasselbalch H, Lisse IM, Ersboll AK, Engelmann MD. T-lymphocyte subsets, thymic size and breastfeeding in infancy. Pediatr Allergy Immunol 2004; 15: 127-132.
33 Sinha A, Madden J, Ross-Degnan D, Soumerai S, Platt R. Reduced risk of neonatal respiratory infections among breastfed girls but not boys. Pediatrics 2003; 112: e303.

34 von Mutius E. Influences in allergy: epidemiology and the environment. I Allergy Clin Immunol 2004; 113: 373-379. 